\title{
Tarımsal Kooperatif Yöneticilerinin İklim Değişikliği ve Yenilenebilir Enerji Farkındalıkları: Çanakkale İli Örneği
}

\author{
Mustafa Yıldırım ${ }^{1}$ Bengü Everest ${ }^{2 *}$
}

\author{
${ }^{1}$ Ticaret Bakanlığı, Esnaf, Sanatkarlar ve Kooperatifçilik Genel Müdürlüğü, Ankara. \\ ${ }^{2}$ Çanakkale Onsekiz Mart Üniversitesi, Ziraat Fakültesi, Tarım Ekonomisi Bölümü, Çanakkale. \\ *Sorumlu yazar: beverest@comu.edu.tr \\ ${ }^{1}$ https://orcid.org/0000-0001-5832-3652, ${ }^{2}$ https://orcid.org/0000-0003-4301-9337
}

Geliş Tarihi: 08.05.2020

Kabul Tarihi: 02.07.2020

\section{$\ddot{O} z$}

$\mathrm{Bu}$ çalışmada kooperatif yöneticilerinin iklim değişikliği ile yenilenebilir enerji bilinç düzeylerinin belirlenmesi amaçlanmıştır. Bu amaçla ilk olarak kooperatif yöneticilerinin sosyo-ekonomik özellikleri tespit edilmiştir. Buna göre kooperatif yöneticileri orta yaşlı, geneli ilkokul mezunu olan ve orta ölçekte tarımsal üretim yapan çifţilerden oluşmaktadır. Çalışmada kooperatif yöneticilerinde iklim değiş̧ikliği ile ilgili bir bilinç ve endişenin var olduğu bulunmuştur. Yöneticilerin önemli bir bölümü iklim değişikliği ile mücadele konusunda eğitim almaya isteklidirler. Ayrıca yenilenebilir enerjiye ilişkin farkındalık düzeyi de orta düzeydedir. Çalışmada kooperatif yöneticilerinin iklim değişikliği ve yenilenebilir enerji bilinçleri Friedman testi ile analiz edilmiştir. Test sonuçlarına göre kooperatif yöneticilerinin iklim değişikliği ve yenilenebilir enerji farkındalıkları arasında istatistiki olarak önemli farklılıklar bulunmuştur. Elde edilen bulgulara göre politika yapıcılar ve üniversite tarafindan bölgedeki kooperatif yöneticilerine ve çiftçilere iklim değişikliği, yenilenebilir enerji ve kooperatifçilik konularında yayım programlarının hazırlanması ile kamu yararı sağlanacaktır.

Anahtar Kelimeler: İklim Değişikliği, Yenilenebilir Enerji, Bilinç, Kooperatif Yöneticisi, Çanakkale.

\section{Renewable Energy Awareness of Agricultural Cooperatives: The Case of Çanakkale Province}

Abstract

In this study, it is aimed to determine the renewable energy and climate change awareness levels of cooperative managers. For this purpose, firstly, socio-economic characteristics of cooperative managers were determined. Accordingly, cooperative managers are middle-aged, general primary school graduates and middlescale agricultural producers. In the study, it was found that there is an awareness and concern about climate change in cooperative managers. A significant number of managers are willing to receive training on combating climate change. Also, the level of awareness about renewable energy is medium. In the study, climate change and renewable energy consciousnesses of cooperative managers were analyzed with Friedman test. According to the test results, statistically significant differences were found between cooperative managers' climate change and renewable energy awareness. According to the findings, preparing extension programs on climate change, renewable energy and cooperatives by policy makers and the university for cooperative managers and farmers in the region will be provide public benefit.

Keywords: Climate Change, Renewable Energy, Consciousness, Cooperative Manager, Çanakkale.

\section{Giriş}

Enerji ihtiyacı günümüzde en çok tartışılan konuların başında gelmektedir. Ülkeler enerji ihtiyaçlarını ağırlıklı olarak fosil yakıtlardan karşılamaktadır. Fosil yakıtların yoğun kullanımı da iklim değişikliğini beraberinde getirmiştir. Dünyada fosil yakıt rezervleri sınırlı olmasına karşıllk dünya enerji ihtiyacı da giderek artmaktadır. Gerek iklim değişikliği ile mücadele için gerekse ihtiyaç duyulan enerjinin sağlanması için yenilenebilir enerji (YE) kaynaklarının kullanımı önemlidir.

Küresel ölçekte bir çevre sorununun ötesinde bir mesele olan iklim değişikliği, uzun dönemde dünyayı etkilemeye devam edecektir. Yakın gelecekte gezegenin sıcaklığında artış ve yağış biçimlerinde değişikliklerle karşı karşıya kalacağı bugün bilimsel çalışmalarla kanıtlanmıştır (Boko et al., 2018; Parrr, 2019; Seneviratne et al., 2017).

Diğer taraftan küresel anlamda bütün ülkelerin ortak sorunu olan iklim değişikliği konusunda farkındalık giderek artmaktadır. Kamu kurum ve kuruluşları, sivil toplum örgütleri ve bireyler iklim 
değişikliği ile mücadele etmenin çeşitli yollarını aramaktadırlar. İklim değişikliği ile mücadelede dünya genelinde yaygınlaştırılmaya çalışılan politikaların başında yenilenebilir enerji kullanımının arttırılması gelmektedir. Literatürde iklim değişikliği ile mücadelede yenilenebilir enerjinin önemini ele alan çalışmalara rastlamak mümkündür (Elum and Momodu, 2017; Kardooni et al., 2018; Owusu and Asumadu-Sarkodie, 2016; Quaschning, 2019).

Ulusal İklim Değişikliği Stratejisi'nde; Türkiye'de 2023 yılına kadar toplam elektrik enerjisi üretiminde yenilenebilir enerji payının \%30'a çıkarılacağı hedeflenmiştir. Türkiye'nin yerli kaynakları olan kömür, hidroelektrik, rüzgâr, jeotermal ve güneş enerjisi başta olmak üzere, çeşitli enerji kaynaklarından, enerji arz güvenliği ve iklim değişikliği hedefleri doğrultusunda en üst düzeyde faydalanması gerekmektedir.

Dünya genelinde yenilenebilir enerji kullanımı yaygın olarak kooperatifler aracıllı̆ı ile olmaktadır. Türkiye'de ise yenilenebilir enerji konusunda faaliyet gösteren kooperatif sayısı oldukça azdır. Hatta ortaklarına yenilenebilir enerji konusunda hizmet veren bir tarımsal kooperatife hiç rastlanılmamıştır. Türkiye'nin İklim Değişikliği Uyum Stratejisi ve Eylem Planı 2011-2023'de tarım sektörü ile ilgili hedefler mevcuttur. Bu hedeflerden biri "tarım sektörüne iklim değişikliğinin etkileri ve uyum yaklaşımları konusunda sivil toplumun bilinçlendirilmesi”dir. Bu kapsamda kooperatifçilik faaliyetlerinin geliştirilip, yaygınlaştırılmasının sağlanması, birlik ve kooperatiflerin iklim değişikliğinin etkilerine uyum konusunda bilinçlendirilmeleri ve kapasitelerinin artırılması hedeflenmiştir.

Toplum için var olan kooperatiflerin asıl amacı sermaye birikiminden ziyade ortaklarının kalkınmasıdır. Enerji bağımlılığının yüksek düzeyde olduğu Türkiye'de toplumsal sorumluluk bilincine sahip kooperatiflerin faaliyet göstermelerinin hem enerji piyasasında alternatif girişimlerin yer alması hem de vatandaşın ülke kalkınmasına katkı sağlaması açısından önem arz etmektedir (Ayanoğlu, 2018). Tarımsal kooperatifler aracılığı ile yenilenebilir enerji kaynaklarından elektrik üretme imkanı vardır (Troya Çevre Derneği, 2019). Yenilenebilir enerji kooperatiflerinin, genellikle yerel girişimler tarafindan kurularak yerel halkın gelirini arttırdığı, gelir dağılımında adaletin sağlanmasına katkı sağladığı, yerel üretim olduğu için elektriğin nakli sırasındaki kayıpları önlediği ve çevreyle dost bir girişim olduğu bilinmektedir (Cebeci, 2018). Yenilenebilir enerji yatırımlarının teşviki için ülkemizdeki kredi, hibe, vergisel destekleri ve mevzuatı düzenleyen devlet kurumlarının koordine bir şekilde çalışması gerekmektedir (Akçay ve Bilgin, 2017). Küresel iklim değişikliği ile mücadelede çiftçi katılımı, adaptasyonu ve farkındalığı önemli olup (Şimşek ve Tuncer, 2018) bunun için sulama sistemlerinin modernleştirilmesi, işletmelerinin verimliliğinin arttırılması ile yenilenebilir enerji üretiminin geliştirilmesi ve finanse edilmesi gerekmektedir (Gürel ve Şenel, 2010). Politikacilar, bankacılar, potansiyel ortaklar ve halk arasında kooperatif işletme modeli hakkında farkındalığın olmaması, yenilenebilir enerji kooperatiflerinin gelişimi için ciddi bir engeldir. Bazı ülkelerde, özellikle Doğu Avrupa'da, kooperatif işletme modeli "eski moda" ve "sosyalist" imgelerle ilişkilendirilmektedir (Huybrechts ve Mertens, 2014). Yenilenebilir enerji kaynakları konusunda bilgi düzeyinin az olması söz konusu kaynakların bilinçsiz bir şekilde kullanılmasına sebep olmaktadır (Çakırlar, 2015). Yenilenebilir enerji farkındalığında çevre konusunda bir ders alanların farkındalıkları yüksektir (Can ve ark., 2019). Yenilenebilir enerji farkındalı̆̆ının arttırılmasında eğitimin faydalı olacağı düşünülmektedir (Cebesoy ve Karışan, 2017; Sarıkaya, 2019; İpekoğlu vd., 2014; Çelikler vd., 2017; Durkaya ve Durkaya, 2018; Tok vd., 2017; Türkmenoğlu, 2016; Saraç ve Bedir, 2014; Zografakis vd., 2010).

$\mathrm{Bu}$ çalışmada tarımsal kooperatif yöneticilerinin iklim değişikliği ve YE farkındalıklarının ortaya konması amaçlanmıştır. Bu amaçla tarımsal kalkınma kooperatifleri yöneticileri ile anket çalışması yapılarak kooperatiflerin iklim değişikliği ile yenilenebilir enerji farkındalıkları ortaya konmuştur. Tarımsal kalkınma kooperatifleri yöneticileriyle daha önce böyle bir çalışmanın yapılmamış olması çalışmanın özgünlügü ortaya koymaktadır.

\section{Materyal ve Yöntem \\ Materyal}

Çanakkale ilindeki Tarımsal Kalkınma Kooperatifleri yöneticileri araştırmanın popülasyonunu oluşturmuştur. Söz konusu popülasyonun örnek hacmi aşağıdaki formüle göre belirlenmiştir (Newbold, 1995). 


$$
\begin{gathered}
\mathrm{n}=\frac{\mathrm{Np}(1-\mathrm{p})}{(\mathrm{N}-1) \sigma^{2} \mathrm{px}+\mathrm{p}(1-\mathrm{p})} \\
\mathrm{n}=\text { Örneğe çıkan kooperatif sayısı } \\
\mathrm{N}=\text { Ana kitle büyüklüğ̈̈ } \\
\mathrm{p}=\text { Ana kitle oranı } \\
\sigma^{2} \mathrm{px}=\text { Ana kitle oranının varyansı }
\end{gathered}
$$

\begin{tabular}{|c|c|c|}
\hline İlçe Adı & $\begin{array}{l}\text { Tarımsal Kalkınma Kooperatifi } \\
\text { Sayısı }\end{array}$ & $\begin{array}{c}\text { Örneğe Çıkan Kooperatif Yöneticisi } \\
\text { Sayısı }\end{array}$ \\
\hline Ayvacık & 14 & $\begin{array}{ll} & 3\end{array}$ \\
\hline Bayramiç & 30 & 5 \\
\hline Biga & 81 & 15 \\
\hline Çan & 40 & 7 \\
\hline Eceabat & 6 & 1 \\
\hline Ezine & 12 & 2 \\
\hline Gelibolu & 21 & 4 \\
\hline Lapseki & 22 & 4 \\
\hline Merkez & 18 & 3 \\
\hline Yenice & 63 & 11 \\
\hline Toplam & 307 & 55 \\
\hline
\end{tabular}

Örnek hacmi 0.10 hata payı ve \% 90 güven aralığı için 55 olarak belirlenmiştir. Belirlenin örnek hacmi ilçeler arasında oransal olarak dağıtılmıştır. Buna göre anket sayısının ilçelere göre dağılımı aşă̆ıdaki gibidir.

Çizelge 1. Görüşülen Kooperatiflerin İlçelere Göre Dağılımı

\section{Yöntem}

Çalışmada kullanılan yöntemlerin belirlenmesi için öncelikle verilerin parametrik olup olmadığına bakılmıştır. Verilerin normallik gösterip göstermediği Shapiro-Wilk testi ile kontrol edilmiştir. Mevcut analiz verilerin normal olarak dağılmadığını ortaya koymuştur $(p<0.05)$. başka bir deyişle veriler parametrik değildir. Bu nedenle istatistiksel değerlendirmelerde parametrik olmayan testler kullanılmıştır.

İkiden fazla bağımlı gruplar için uygulanan Friedman testi, iki yönlü varyans analizinin parametrik olmayan karşılığıdır. Doğallık ve varyansların homojenliği varsayımı gerektirmemesi ve ölçüm değerlerine büyüklük sıra sayılarının verilmesi bu testin temel özelliğidir (Söğüt vd., 2015). İki yönlü varyans analizinde model

$\mathrm{X} i j=\mu+\beta i+\gamma j+\varepsilon i j$

$\mathrm{i}=1,2, \ldots, \mathrm{n}$

$\mathrm{j}=1,2, \ldots, \mathrm{c}$ şeklinde ifade edilir.

Burada; Xij : $i$. blokta $j$. işlem için gözlem değerleri, $\mu$ : Genel ortalama, $\beta \mathrm{i}: i$. blok etkisi, $\gamma j$ : $j$. grup etkisi, $\varepsilon$ ij: Hata terimi, n: Blok sayısı, c: grup sayısıdır (Gamgam ve Altunkaynak, 2008).

Friedman (1937)'nin önerdiği test istatistiği ise şu şekildedir:

$S=\frac{12}{n c(c+1)} \sum_{j=1}^{c} R j^{2}-3 n(c+1)$

Burada; $R_{j}: \mathrm{j}$. gruba ait sira sayıları toplamı, $\mathrm{Rj}: \mathrm{j}$. gruba ait sira sayıları ortalamas1, R: Sira sayıları genel toplamıdır. Friedman test istatistiği c ve n'nin çeşitli değerleri için örnekleme dağılımı halini almıştır. Friedman test hipotezleri ise şu şekilde belirlenmiştir;

$\mathrm{H}_{0}$ : Kooperatif yöneticilerinin iklim değişikliği ve YE farkındalıkları arasında fark yoktur, 
$\mathrm{H}_{1}$ : Kooperatif yöneticilerinin iklim değişikliği ve YE farkındalıkları arasında fark vardır.

Bulgular

Kooperatif Yöneticilerinin Sosyo-Ekonomik Özellikleri

Çalışma kapsamında görüşülen kooperatif yöneticilerinin ortalama yaş seviyesi 49 yıl, eğitim seviyeleri ağırlıklı olarak ilkokul $(\% 56,4)$, kooperatife ortaklık y1lı ortalama 17 yıl, yöneticilik deneyimleri ortalama 10 y1l bulunmuştur. Kooperatif yöneticilerinin \%78,2'si son bir yılda tarımla ilgili bir toplantıya katılmıştır. Yöneticilerin \%18,2'si tarımsal yayınları takip etmekte ve \%78,2'si bilgiye ulaşmada internetten faydalanmaktadırlar. Yöneticilerin \%54,5'i kooperatifçilik konusunda eğitim almıştır. Kooperatif yöneticilerinin sahip oldukları arazi miktarı çoğunlukla 100 dekarın altındadır (\%81,8), \%34,5'inin yıllık tarımsal gelirleri 20.001-50.000 TL arasındadır ve \%61,8'inin tarım dışı geliri bulunmaktadır (Çizelge 2).

Çizelge 2. Sosyo-Ekonomik Özellikler

\begin{tabular}{|c|c|c|}
\hline Kriterler & Say1 & Oran $(\%)$ \\
\hline \multicolumn{3}{|l|}{ Yaş Seviyesi (Yll) } \\
\hline$\leq 49$ & 27 & 49,1 \\
\hline$>49$ & 28 & 50,9 \\
\hline \multicolumn{3}{|c|}{ Min:29, Mak:70, Mean:49,34, S. Sapma:9,3 } \\
\hline \multicolumn{3}{|c|}{ Ĕgitim Durumu } \\
\hline Illkokul & 31 & 56,4 \\
\hline Ortaokul & 8 & 14,5 \\
\hline Lise & 13 & 23,6 \\
\hline Üniversite & 3 & 5,5 \\
\hline \multicolumn{3}{|c|}{ Kooperatife Ortaklık Yılı } \\
\hline$\leq 16$ & 35 & 63,6 \\
\hline$>16$ & 20 & 36,4 \\
\hline \multicolumn{3}{|c|}{ Min:1, Mak:46, Mean:16,87, S. Sapma:9,97 } \\
\hline \multicolumn{3}{|c|}{ Yöneticilik Deneyimi (Yll) } \\
\hline$<10$ & 23 & 41,8 \\
\hline$\geq 10$ & 32 & 58,2 \\
\hline \multicolumn{3}{|c|}{ Min:1, Mak:30, Mean:9,74, S. Sapma:6,71 } \\
\hline \multicolumn{3}{|c|}{ Son 1 Yllda Tarımsal Bir Toplantiya Katılma } \\
\hline Katılan & 43 & 78,2 \\
\hline Katılmayan & 12 & 21,8 \\
\hline \multicolumn{3}{|c|}{ Tarımsal Dergi, Gazete vb. Yayınları Takip Etme } \\
\hline Takip Eden & 10 & 18,2 \\
\hline Takip Etmeyen & 45 & 81,8 \\
\hline \multicolumn{3}{|c|}{ Bilgiye Ulaşmada İnternet Kullanma } \\
\hline Kullanan & 43 & 78,2 \\
\hline Kullanmayan & 12 & 21,8 \\
\hline \multicolumn{3}{|c|}{ Kooperatifçilik Ĕ̈itimi Alma Durumu } \\
\hline Alan & 30 & 54,5 \\
\hline Almayan & 25 & 45,5 \\
\hline \multicolumn{3}{|l|}{ Arazi Miktarı(da) } \\
\hline$\leq 100$ & 45 & 81,8 \\
\hline$>100$ & 10 & 18,2 \\
\hline \multicolumn{3}{|c|}{ Ylllık Tarımsal Gelir (TL) } \\
\hline$<10.000$ & 6 & 10,9 \\
\hline $10.001-20.000$ & 12 & 21,8 \\
\hline $20.001-50.000$ & 19 & 34,5 \\
\hline $50.001-100.000$ & 14 & 25,5 \\
\hline$>100.000$ & 4 & 7,3 \\
\hline \multicolumn{3}{|c|}{ Tarım Dışı Gelir Varlı̆ğ } \\
\hline Var & 34 & 61,8 \\
\hline Yok & 21 & 38,2 \\
\hline
\end{tabular}




\section{Kooperatif Yöneticilerinin İklim Değişikliği Farkındalıkları}

Bireylerin iklim değişikliği kavramına yönelik düşünceleri bu konudaki adaptasyon çalışmaları için önem arz etmektedir. Kooperatif yöneticilerinin yaklaşık \%42'si iklim değişikliği dendiği zaman "mevsimlerin değişmesi"ni anlamaktadırlar. Bunu sırasıyla "kuraklık" $(\% 32,7)$ ve "küresel ısınma" (\%10,9) kavramları takip etmektedir (Çizelge 3).

Çizelge 3. Yöneticilerin İklim Değişikliği Farkındalıkları

\begin{tabular}{|l|r|r|}
\hline Kavram & Sayl & Oran (\%) \\
\hline Mevsimlerin değişmesi & 23 & 41,8 \\
\hline Küresel ısınma & 6 & 10,9 \\
\hline Kuraklık & 18 & 32,7 \\
\hline Hava kirlilĭği & 1 & 1,8 \\
\hline Ozon tabakasının incelmesi & 1 & 1,8 \\
\hline Yağış rejiminde değişme & 3 & 5,5 \\
\hline Çevre kirliliği & 3 & 5,5 \\
\hline Toplam & 55 & 100,0 \\
\hline
\end{tabular}

Kooperatiflerin bulunduğu köylerin \%43,6'sında son 3 yılda iklim değişikline bağlı bir tabii afet yaşanmışken \%56,4'ünde bir tabii afet yaşanmamıştır (Çizelge 4). İklim değişikliğine bağlı tabii afet yaşayanların ise $\% 87,5$ 'i kuraklık, $\% 8,3$ 'ü yangın ve $\% 4,2$ 'si sel yaşamışlardır.

Çizelge 4. İklim Değişikliğine Bağlı Tabii Afet Yaşama Durumu

\begin{tabular}{|l|r|r|}
\hline Kriter & Sayl & Oran (\%) \\
\hline Evet & 24 & 43,6 \\
\hline Hayır & 31 & 56,4 \\
\hline Toplam & 55 & 100,0 \\
\hline
\end{tabular}

Bireylerin iklim değişikliğinden endişeleniyor olmaları iklim değişikliği ile mücadelede önemli bir göstergedir. Kooperatif yöneticilerinin neredeyse tamamı iklim değişikliğinden endişelenmektedir ve $\% 74,5^{\prime}$ i iklim değişikliği ile mücadele yöntemleri konusunda eğitim almaya isteklidirler (Çizelge 5).

Çizelge 5. İklim Değişikliğine ilişkin Bilinçlenme İsteği

\begin{tabular}{|l|r|r|r|}
\hline Kriter & Sayl & Oran (\%) \\
\hline İklim değişikliğinden endişelenme durumu & 53 & 96,4 \\
\hline Evet & 2 & 3,6 \\
\hline Hayır & 41 & 74,5 \\
\hline İklim değişikliği ile mücadele konusunda eğitim alma isteği & \multicolumn{3}{|c|}{} \\
\hline Evet & 14 & 25,5 \\
\hline Hayır & &
\end{tabular}

Kooperatif Yöneticilerinin Yenilenebilir Enerji Farkındalıkları

Kooperatif yöneticilerinin yenilenebilir enerji farkındalıklarını ölçmek için ilk olarak yenilenebilir enerji kaynaklarına ilişkin bilgi seviyeleri araştırılmıştır. Beşli likert ölçeğini skor hesaplamasına göre Çanakkale ilinde yenilenebilir enerji dendiği zaman kooperatif yöneticileri tarafından en çok bilinen enerji kaynağı "güneş enerjisi"dir. Bunu sırasıyla "rüzgar" ve "biyogaz" enerji kaynakları takip etmektedir. Bölgede en az bilinen yenilenebilir enerji kaynağı ise "dalga, akıntı, gelgit” kaynağıdır (Çizelge 6). 
Çizelge 6. Kooperatif Yöneticilerinin YE Bilinçleri

\begin{tabular}{|c|c|c|c|c|c|c|c|}
\hline Kriter & $\mathrm{Hiç}(5)$ & Kötü (4) & Orta (3) & $\dot{I y i}(2)$ & Çok iyi (1) & Skor & Stralama \\
\hline Güneș enerjisi & 1,8 & 56,4 & 12,7 & 20,0 & 9,1 & 278,2 & 1,0 \\
\hline Rüzgar enerjisi & 3,6 & 70,9 & 7,3 & 16,4 & 1,8 & 241,8 & 2,0 \\
\hline Hidrolik (su gücü) & 16,4 & 70,9 & 3,6 & 7,3 & 1,8 & 207,3 & 4,0 \\
\hline Jeotermal & 50,9 & 38,2 & 3,6 & 7,3 & 0,0 & 167,3 & $\overline{6,0}$ \\
\hline Biyogaz & 38,2 & 40,0 & 0,0 & 18,2 & 3,6 & 209,1 & 3,0 \\
\hline Biyodizel & 38,2 & 49,1 & 0,0 & 10,9 & 1,8 & 189,1 & 5,0 \\
\hline Dalga, akıntı, gelgit & 60,0 & 36,4 & 0,0 & 3,6 & 0,0 & 147,3 & 7,0 \\
\hline
\end{tabular}

Yine kooperatif yöneticilerinin YE farkındalıkları için aşağıdaki ifadelere hangi düzeyde katıldıkları likert ölçeği ile sorulmuştur. Buna göre kooperatif yöneticileri YE denildiğinde ilk olarak YE’nin “temiz enerji” olduğunu düşünmektedirler. Bunu YE'nin "güvenilir" olduğu takip etmektedir. Kooperatif yöneticileri en son sırada "YE için ücret ödeyebileceklerini" ifade etmişlerdir (Çizelge 7).

Çizelge 7. Kooperatif Yöneticilerinin YE Yaklaşımları

\begin{tabular}{|c|c|c|c|c|c|c|c|}
\hline Kriter & 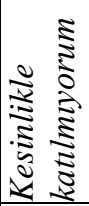 & 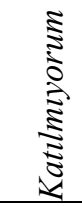 & 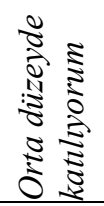 & 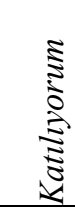 & 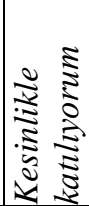 & $\frac{\bar{a}}{5}$ & 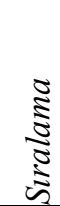 \\
\hline YE temizdir & 0,0 & 1,8 & 9,1 & $\overline{36,4}$ & 52,7 & 440,0 & 1,0 \\
\hline YE güvenilirdir & 0,0 & 3,6 & 20,0 & 38,2 & 38,2 & 410,9 & 2,0 \\
\hline YE tükenmezdir & 1,8 & 21,8 & 14,5 & 34,5 & 27,3 & 363,6 & 5,0 \\
\hline YE kullanımında kooperatifler öncü olmalıdır & 5,5 & 10,9 & 7,3 & 43,6 & 32,7 & 387,3 & $\overline{3,0}$ \\
\hline Gelecekte enerji ihtiyacının tamamı YE'den karşılanacaktır & 3,6 & 12,7 & 21,8 & 38,2 & 23,6 & 365,5 & $\overline{4,0}$ \\
\hline YE kullanmak için para ödemeyi kabul ederim & 12,7 & 14,5 & 10,9 & 47,3 & 14,5 & 336,4 & 6,0 \\
\hline
\end{tabular}

YE üretiminin kooperatifler tarafindan yapılıyor olması dünya için olmasa da Türkiye için yeni bir durumdur. Bu kapsamda kooperatif yöneticilerine YE üretimi ile kooperatifler arasındaki ilişkiyi bilme durumları analiz edilmiştir. Elde edilen bulgulara göre yöneticilerin sadece $\% 25,5{ }^{\prime} i$ YE’nin kooperatifler tarafindan da üretilebileceğinden haberdardır (Çizelge 8).

Çizelge 8. YE Üretimi ile Kooperatifler Arasındaki İlişkiyi Bilme Durumu

\begin{tabular}{|l|r|r|}
\hline Kriter & Sayl & Oran (\%) \\
\hline Bilen & 14 & 25,5 \\
\hline Bilmeyen & 41 & 74,5 \\
\hline Toplam & 55 & 100,0 \\
\hline
\end{tabular}

Kooperatif yöneticilerinin iklim değişikliği ve YE farkındalıklarının ele alındığı çalışmada yöneticilerin;

- İklim değişikliği konusunda eğitim alma istekleri (IDD-EĞİTIM),

- YE üretimi ile kooperatifler arasındaki ilişkiyi bilme durumları (YE-KOOP) ve

- Gelecekte YE için yatırım yapma düşünceleri (YE-YATIRIM) arasındaki ilişkiye Friedman

Testi uygulanmıştır. Friedman test hipotezleri ise şu şekilde belirlenmiştir;

$\mathrm{H}_{0}$ : Kooperatif yöneticilerinin iklim değişikliği ve YE farkındalıkları arasında fark yoktur,

$\mathrm{H}_{1}$ : Kooperatif yöneticilerinin iklim değişikliği ve YE farkındalıkları arasında fark vardır.

Değişkenlere ilişkin tanımlayıcı istatistikler Çizelge 9'da sunulmuştur. 
Çizelge 9. Bağımlı Değişkenlere İlişkin Tanıtıcı İstatistikler

\begin{tabular}{|l|r|r|r|r|r|r|r|}
\hline & & & & \multicolumn{3}{|c|}{ Percentiles } \\
\cline { 5 - 9 } Değişkenler & Mean & Std. Deviation & Minimum & Maximum & 25th & 50th (Median) & 75th \\
\hline İD-EĞİTIM & 1,2545 &, 43962 & 1,00 & 2,00 & 1,00 & 1,00 & 2,00 \\
\hline YE-KOOP & 1,7455 &, 43962 & 1,00 & 2,00 & 1,00 & 2,00 & 2,00 \\
\hline YE-YATIRIM & 1,3818 &, 49031 & 1,00 & 2,00 & 1,00 & 1,00 & 2,00 \\
\hline
\end{tabular}

Çizelge $10^{`}$ da Friedman testi sonucuna göre ki-kare değeri 24,542 olarak bulunmuştur. Ayrıca kooperatif yöneticilerinin verdiği cevaplara göre değişkenler arasında istatistiksel olarak önemli farkl111k bulunmuştur $(\mathrm{p}<0.05)$.

Çizelge 10. Bağımlı Değiş̧kenler İçin Friedman İstatistiği

\begin{tabular}{|l|r|}
\hline Nest istatistiği & 55 \\
\hline$p$ & $\chi^{2}=24,542$ \\
\hline
\end{tabular}

Friedman testi değişkenler arasında istatistiki olarak anlamlı bir ilişkinin olduğunu söylemekte ancak hangi değişkenler arasında bir ilişki olduğunu söylememektedir. Bu durumda yapılacak PostHoc analizi ile çoklu karşılaştırma yapılarak hangi değişkenler arasında ilişki olduğu ortaya çıkacaktır. Çizelge 11'de verilen çoklu karşılaştırma istatistiğine göre "YE KOOP-YE YATIRIM" ile "YE KOOP-İD EĞİTIM" arasında bir fark bulunmuştur. Burada farklılı̆̆ 1 yaratan ise kooperatif yöneticilerinin "YE üretimi ile kooperatifler arasındaki ilişkiyi bilme durumları (YE-KOOP)"dır.

Çizelge 11. Bağımlı Değişkenlerin Çoklu Karşılaştırması

\begin{tabular}{|l|r|r|r|r|}
\hline Değişkeler & $\begin{array}{r}\text { Test } \\
\text { istatistiğ }\end{array}$ & Std. Hata & Std. Test İstatistiği & Anlamlıllk \\
\hline YE KOOP-YE YATIRIM & $-0,364$ & 0,103 & $-3,536$ & 0,001 \\
\hline YE KOOP-İD EĞİTiM & 0,491 & 0,103 & 4,773 & 0,000 \\
\hline YE YATIRIM-İD EĞITIM & 0,127 & 0,103 & 1,237 & 0,648 \\
\hline
\end{tabular}

İkili karşılaştırmaların verildiği Şekil 1'e göre de kooperatif yöneticilerinin "YE üretimi ile kooperatifler arasındaki ilişkiyi bilme durumları (YE-KOOP)" diğer iki değişkenden farklı bir konumdadir.

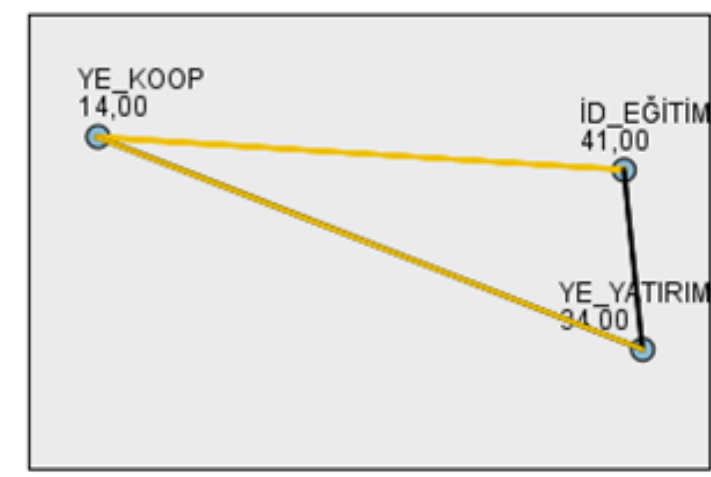

Şekil 1. Bağımlı Değişkenlerin İkili Karşılaştırmaları

\section{Sonuç ve Öneriler}

Kooperatif yöneticilerinin sosyo-ekonomik özellikleri ile iklim değişikliği ve YE farkındalıklarının analiz edildiği bu çalışmadan şu çıkarımlar ve öneriler elde edilmiştir. Çanakkale ilindeki kooperatif yöneticileri orta yaş seviyesinde, genelde ilkokul mezunu, kooperatif yöneticiliği deneyimleri uzun olan ve orta ölçekte tarımsal üretim yapan çiftçilerden oluşmaktadır. Aynı zamanda 
çiftçilik de yapan kooperatif yöneticileri iklim değişikliğinden endişe duymaktadırlar ve büyük bir kısmı iklim değiş̧ikliği ile mücadele konusunda eğitim almaya isteklidirler. Çiftçilerin bu konuda istekli olmaları bölgede tarım sektörünü de tehdit eden iklim değişikliği konusunda eğitimler verilmesini gerekli kılmaktadır. Bu bağlamda iklim değişikliği ile mücadele eden kamu kurum ve kuruluşları ile üniversite iş birliğinin sağlanması önerilir.

İklim değişikliği ile mücadele etmede kullanılabilecek en etkili araç yenilenebilir enerjinin kullanımıdır. Elde edilen bulgulara göre bölgedeki kooperatif yöneticilerinin YE ile ilgili orta düzeyde sayılabilecek bir bilgisi vardır. Ancak bu bilginin önemli eksikleri tespit edilmiştir. Örneğin kooperatif yöneticilerinin çok azı YE'nin kooperatifler tarafından da üretilebileceğini bilmektedirler. Yapılan istatistiki analizlerde YE'nin kooperatifler tarafından üretilebileceğini bilen kooperatif yöneticilerinin varlığı iklim değişikliği ve YE farkındalığı üzerinde etkili olmaktadır. O halde bölgede yenilenebilir enerjinin kullanımı ile kooperatifler arasındaki ilişki bilincinin artırılmasına yönelik yayım çalışmalarına ihtiyaç vardır. Bu yayım çalışmalarının başta kooperatif yöneticileri olmak üzere kooperatif ortaklarına ve toplumun diğer üyelerine yönelik olarak yapılması iklim değişikliği ile mücadelede etkili olabilir.

Teşekkür: Bu çalışmayı FYL-2019-3053 kodlu proje ile destekleyen Çanakkale Onsekiz Mart Üniversitesi Bilimsel Araştırma Projeleri Koordinasyon Birimine teşekkürlerimizi sunarız.

\section{Kaynaklar}

Akçay, V. H., Bilgin, S., 2017. Sürdürülebilir kalkınma politikası açısından yenilenebilir enerji kooperatifçiliğine yönelik mali teşviklerin önemi. Üçüncü Sektör Sosyal Ekonomi Dergisi. 52 Özel say1:867-896.

Ayanoğlu G. G. D., 2018. Yenilenebilir Enerji Yatırımında Alternatif Bir Model: Yenilenebilir Enerji Üretim Kooperatifleri. Cinius Yayınları. 116-117.

Boko, M., Niang, I., Nyong, A., Vogel, A., Githeko, A., Medany, M., ... \& Yanda, P. Z. (2018). Africa Climate Change 2007: Impacts, Adaptation and Vulnerability: Contribution of Working Group II to the Fourth Assessment Report of the Intergovernmental Panel on Climate Change.

Can, S., Görecek Baybars, M., Can, Ş., 2019. Sınıf öğretmeni adaylarının yenilenebilir enerji farkındalık düzeylerinin bazı değişkenler açısından incelenmesi. 6. Uluslararası Multidisipliner Çalışmaları Kongresi. s. 283. 26-27 Nisan, Gaziantep.

Cebeci, A. N., 2018. Renewable energy cooperatives in the world, the natural miracle in Turkey on the requirement of solar energy cooperatives. Journal of Strategic Research in Social Science. 4 (2): 1-22.

Cebesoy, Ü. B., Karışan, D., 2017. Fen Bilgisi Öğretmen adaylarının yenilenebilir enerji kaynaklarına yönelik bilgilerinin, tutumlarının ve bu kaynakların öğretimi konusundaki öz-yeterlik algılarının incelenmesi. Yüzüncü Yıl Üniversitesi Eğitim Fakültesi Dergisi. 14(1), 1377-1415.

Çakırlar, E., 2015. Ortaöğretim öğrencilerinin yenilenebilir enerji kaynakları konusundaki farkındalık düzeylerinin belirlenmesi. Hacettepe Üniversitesi Eğitim Bilimleri Enstitüsü, Ortaöğretim Fen ve Matematik Alanlar Eğitimi Anabilim Dalı, Yüksek Lisans Tezi. $102 \mathrm{~s}$.

Çelikler, D., Aksan, Z., Yılmaz, A., 2017. Ortaokul Öğrencilerinin Yenilenebilir Enerji Kaynakları Konusundaki Farkındalıkları. Uluslararası EJER Kongresi. 67-72. 11-14 Mayıs, Denizli.

Durkaya, B., Durkaya, A., 2018. Küresel ısınma farkındalığı "Bartın Üniversitesi öğrencileri örneğı”. Bartın Orman Fakültesi Dergisi, 20 (1): 128-144.

Elum, Z. A., Momodu, A. S., 2017. Climate change mitigation and renewable energy for sustainable development in Nigeria: A discourse approach. Renewable and Sustainable Energy Reviews, 76, 72-80.

Friedman, M., 1937. The use of ranks to avoid the assumption of normality implicit in the analysis of variance. Journal of the American Statistical Associations. 32: 675- 701.

Gamgam, H., Altunkaynak, B., 2008. Parametrik Olmayan Yöntemler SPSS Uygulamalı. Gazi Kitabevi. Ankara.

Gürel, A., Şenel, Z., 2010. Tarım ve iklim değişikliği ilişkisinde alınması gereken önlemlerin tarımsal yayım açısından irdelenmesi. Türkiye IX. Tarım Ekonomisi Kongresi. 22-24 Eylül, Şanlıurfa.

Huybrechts, B., Mertens, S., 2014. The relevance of the cooperative model in the field of renewable energy. Annals of Public and Cooperative Economics. 85(2), 193-212.

İpekoğlu, H. Y., Üçgül, İ., Yakut, G., 2014. Yenilenebilir enerji algısı anketi: Güvenirlik ve geçerliği. SDÜ Yekarum e-Dergi, 2(3).

Kardooni, R., Yusoff, S. B., Kari, F. B., Moeenizadeh, L., 2018. Public opinion on renewable energy technologies and climate change in Peninsular Malaysia. Renewable energy, 116, 659-668.

Newbold, P., 1995. Statistics for Business and Economics, Prentice Hall Inc., USA. Pages 1016. 
Owusu, P. A., Asumadu-Sarkodie, S., 2016. A review of renewable energy sources, sustainability issues and climate change mitigation. Cogent Engineering, 3(1), 1167990.

Parry, M. L., 2019. Climate change and world agriculture. Routledge.

Quaschning, V. V., 2019. Renewable energy and climate change. John Wiley \& Sons.

Saraç, E., Bedir, H., 2014. Sınıf öğretmenlerinin yenilenebilir enerji kaynakları ile ilgili algıları üzerine nitel bir çalışma. Kara Harp Okulu Bilim Dergisi. 24(1), 19-45.

Sarıkaya, A. Ö., 2019. Sosyal bilgiler öğretmen adaylarının yenilenebilir enerji kaynakları hakkındaki farkındalıkları: Betimsel bir çalışma. Afyon Kocatepe Üniversitesi, Sosyal Bilimler Enstitüsü, İlköğretim Anabilim Dalı Yüksek Lisans Tezi. 95s.

Seneviratne, S. I., Nicholls, N., Easterling, D., Goodess, C. M., Kanae, S., Kossin, J., ... \& Reichstein, M. (2017). Changes in climate extremes and their impacts on the natural physical environment.

Söğüt, B., Çelik, Ş., İnci, H., Şengül, T., Daş, A., 2015. Farklı tüy rengine sahip Japon bıldırcınlarda bazı vücut ağırlı̆̆ verilerinin Friedman ve Quade testleriyle belirlenmesi. Türk Tarım ve Doğa Bilimleri Dergisi 2(2): $171-177$.

Şimşek, E., Tuncer, K., (2018). Amasya İli Merkez İlçede Süt Sığırcılığı Yapan Tarım İşletmelerinin SosyoEkonomik Özellikleri ve İklim Değişikliği ile İlgili Düşünceleri. ÇOMÜ Ziraat Fakültesi Dergisi, 6(2), $35-45$.

Tok, G., Cebesoy, Ü. B., Bilican, K., 2017. Sınıf öğretmeni adaylarının iklim değişikliği farkındalıklarının incelenmesi. Batı Anadolu Eğitim Bilimleri Dergisi, 8(2), 23-36.

Troya Çevre Derneği, 2019. Tarımsal Üretimde Yenilenebilir Enerji Kullanımı Rehber Kitabı. Çanakkale.

Türkmenoğlu, H., 2016. Orta ve doğu karadeniz'deki KOBİ'lerde yenilenebilir enerji eğilimi üzerine bir çalışma. Ordu Üniversitesi, Fen Bilimleri Enstitüsü, Yenilenebilir Enerji Anabilim Dalı, Yüksek Lisans Tezi, 60s.

Zografakis, N., Sifaki, E., Pagalou, M., Nikitaki, G., Psarakis, V., Tsagarakis, K. P., 2010. Assessment of public acceptance and willingness to pay for renewable energy sources in Crete. Renewable and Sustainable Energy Reviews. 14(3), 1088-1095. 